\title{
ROBOT AND PLANT SIMULATION FOR AUTOMOTIVE PART PRODUCTION PROCESS DESIGN: A CASE STUDY
}

\author{
Supsomboon, S. \& Varodhomwathana, T. \\ The Sirindhorn International Thai-German Graduate School of Engineering, \\ King Mongkut's University of Technology North Bangkok (KMUTNB), Bangkok, Thailand \\ E-Mail: srisawat.s@tggs.kmutnb.ac.th,v.thitiwat@gmail.com
}

\begin{abstract}
Due to the higher competition in automobile industry, automotive part manufacturers who supply parts have also been challenged to improve the quality of their products to meet customers' requirements. Quality of parts or products could be controlled and improved since the stage of production process design. Efficient production process design could reduce work in process (WIP), wastes, reworks, errors, and failures, which could reduce system cost and increase quality of final products. However, production process design for the process which implements automatic systems is sophisticate due to the complication of the equipment itself and the synchronization requirement. This study presents the use of computer simulations to design an automotive part production process. Two objectives are proposed. The first one is to introduce three dimension robot (3D CAD) simulation for robotic work stations designed to meet the desired cycle time with minimum chance of robot collision and minimum number of robots in the system. The second one is to propose plant simulation for production planning design in order to produce product which could meet the desired capacity and customer needs with minimum number of workers.

(Received in April 2017, accepted in August 2017. This paper was with the authors 1 month for 1 revision.)
\end{abstract}

Key Words: Robot Simulation, Plant Simulation, Production Process Design, Automotive Part Manufacturing

\section{INTRODUCTION}

\subsection{Problem statement}

Thailand is currently in the world's top ten automotive exporter overall and the world's top ten automobile manufacturers. Due to the higher degree of competition in either local or world market, automotive part assembly manufacturers have been challenged by higher standard and requirement of customers. There are many substantial areas of improvement which should be brought into account to achieve customer satisfaction, for example, worker skill enhancement, automation system implementation, quality improvement, wastes and cost deduction, and productivity improvement. The modern production process with advanced robot and automation systems could gain higher potential of success. Computer-aided design systems have played a significant role to assist management in system design and decision making stages. Robot and plant simulations have become very powerful tools in modern manufacturing as they can provide various possible scenarios which could be visualized and tested before actual implementation take place. Besides, robot path simulation is very useful for performance prediction and evaluation in terms of availability and flexibility of robot systems. This study has two objectives. The first one is to propose three dimension robot (3D $\mathrm{CAD})$ simulation for robotic work station design to meet the desired cycle time with minimum chance of robot collision and minimum number of required robots in the system. The second one is to propose plant simulation for production planning design to meet the desired capacity which can satisfy customer needs with minimum number of workers. Robot simulation application is that the work cell concept, developed in Technomatix, was studied 
for the welding arc and welding spot process equipment. A three dimensional model of the cell was designed in NX software. Plant simulation application is that plant simulation or eMPlant is the object oriented simulation tool for discrete event simulation. It has been using in planning and optimization of production and logistics market across many industries from manufacturers like BMW and Daimler-Chrysler to shipyards. Lean thinking is also applied to reduce possible Muda or wastes in the system. Simulation model that we proposed could reduce overproduction, inappropriate processing, waiting, transportation, motion, inventory, and underutilization. Robot and plant simulations are created to design a new production process before implementing system into real production. The objective is to minimize risk of possible errors or failures and possible wastes.

\subsection{Literature review}

In the late 1950s, simulation software was very expensive and rarely used in large companies who could afford such high investment, Andradottir et al. [1]. In the past decade, they are more widely used in many companies in various industries. Simulation models present the great benefits to assist in performance improving, problems solving, including a great help in decision making, Supsomboon and Vajasuvimon [2]. Simulation also provides variety scenarios to utilize production planning, Heinicke and Hickman [3]. It has been used to evaluate performance of a system under different conditions over periods of time before the desired equipment would be installed in real system, Muhammad and Feng [4]. In automotive industry, simulation tools were used to design and improve assembly line to increasing productivity, Ülgen and Upendram [5]. It could also be used to identify bottleneck in assembly process to improve production performance of the system, Trakultongchai et al. [6], Thürer et al. [7].

Robot simulation is one of the essential tools of modern manufacturing as it allows system visualization and testing. A three dimension computer aid design (3D CAD) has been used as an interface to visualize and simulate pre-program robot paths, Neto et al. [8], Curcio et al. [9]. The specific goals of using robot are to reduce setup time, cycle time, and increase flexibility to meet demands of customer. Robot simulation has been wildly used in many areas. Urrea and Kern [10] studied the design, simulation and comparison of the performance of controllers applied to a redundant robot with five degrees of freedom (DOF). Yang et al. [11] presented an autonomous robot control to cope with the robot positioning problem, which is a visual servo approach in context of tile grasping for the EAMA robot.

Cycle time is the period of time required to complete job or task from start to finish in one work station or the total duration of a process from its run time. In production process design, cycle time of each workstation is compared with takt time. If cycle time is longer than takt time, it results in bottlenecks and customer orders could not be filled in time, Deros et al. [12]. In addition, simulation tool was able to use to compare performance of the proposed models in term of utilization, characteristics of work in process (WIP), and ability to meet due date. Technomatix Plant Simulation software was applied to simulate the comparison of two different production models in research of Stankovic et al. [13]. Kadar et al. [14] showed the potential of using simulation model in supporting production planning and scheduling. They built a simulation model which constituted a coherent part of Digital Factory solution. The model was connected to an integrated production planner and job-shop scheduler system. Haider et al. [15] proposed an iterative system improvement strategy to explore the potential of tool room. The essence of the proposed system improvement strategy was Lean concepts and methodologies. The results showed that WIP had been reduced as well as tardiness, and production volumes had improved.

A well establishment of simulation model could be used to improve the understanding of the behavior of the system and with simulation answer all of questions about production could 
be encountered, Maria [16]. Simulation is applied in process design and workstation optimization in manufacturing process to achieve customer demands. Management could use simulation to test all possible solutions to achieve customer demand, Sargent [17], Güçdemir and Selim [18], Lang et al. [19]. Ho [20] studied staged improvement of delivery-orientated production plan using proposes a system dynamics (SD) model was study. A practical problem in the study was a dynamic approach adjusting enterprise's policy for conforming customers' needs. Sasiadek [21] presents theoretical notions related to assembly sequence planning in the process of elements design engineering and design for machines assembly. Kostic et al. [22] describes the development of assembly mate references within the Webbased Virtual Laboratory for collaborative learning in industrial design. Process concerns creation of basic geometric constraints for assembly work. Banduka et al. [23] proposed an integrated lean approach to PFMEA for solving specific shortcomings. Lean approach was integrated in PFMEA.

In this study, simulation models have been presented to illustrate production process design in two steps. Firstly, robot simulation is proposed to design robot work stations. Secondly, plant simulation is presented to design production planning of those robot work stations.

\section{RESEARCH METHODS}

This paper presents a case study of an automotive part manufacturing in Thailand in the process of designing a new production line for new model parts. A new product is an assembly part with many spot points and arc seams: 192 spot welding points and 12 arc welding seams. The product has right and left sides. The right-side part is assembled by 24 components with 96 spot welding points and 8 arc welding seams. The left part is assembled by 22 components with 96 spot welding point and 4 arc welding seams. This new model production is currently required to produce 6,250 sets per month (one set for one car) and the product line is planned to increase capacity up to 8,000 sets per month in the near future. This requirement drives a production process design to increase flexibility and capacity to be able to reach future target. In the design process of these new parts, Lean manufacturing concept and Simulation are applied in order to reduce waste, minimize robot path, avoid robot collision, shorten setup time, and minimize possible unexpected errors before implementing robots into the real system. Generally, the system operated in 2 shifts per day. Shift length and break times are described in the table below.

Table I: Two shifts operation and available time.

\begin{tabular}{|l|c|c|c|c|}
\hline \multicolumn{1}{|c|}{ Periods } & Shift 1 & Time (min) & Shift 2 & Time (min) \\
\hline Shift Length & $8.00 \mathrm{am}-05.30 \mathrm{pm}$ & 570.00 & $8.00 \mathrm{pm}-05.30 \mathrm{am}$ & 570.00 \\
\hline Morning Break & $10.00 \mathrm{am}-10.10 \mathrm{am}$ & 10.00 & $10.00 \mathrm{pm}-10.10 \mathrm{pm}$ & 10.00 \\
\hline $\begin{array}{l}\text { Lunch Break / } \\
\text { Midnight Break }\end{array}$ & 12.00 noon $-1.00 \mathrm{pm}$ & 60.00 & $00.00 \mathrm{am}-1.00 \mathrm{am}$ & 60.00 \\
\hline Afternoon Break & $3.00 \mathrm{pm}-3.10 \mathrm{pm}$ & 10.00 & $03.00 \mathrm{am}-3.10 \mathrm{am}$ & 10.00 \\
\hline Overtime & $05.30 \mathrm{pm}-08.00 \mathrm{pm}$ & 150.00 & $05.30 \mathrm{am}-08.00 \mathrm{am}$ & 150.00 \\
\hline Available time & & 640.00 & & 640.00 \\
\hline
\end{tabular}

The purpose of simulation model is to design this new production process by these 3 robotic welding stations with the total requirement of 8,000 sets per month with the desired takt time. It is assumed that availability losses such as setup times and breakdowns are not considered in this study. After implement the system and availability losses are acquired, they should be taken into account so that the results would be more reliable. Takt time can be calculated as followed. 
Takt time $=$ Available Operating time/Customer Demand

In this case, demand planned for future need is 8,000 sets per month. Working hours and available time are shown in the table above. Therefore, Takt time is calculated as followed.

Takt time $=(30$ days $\times((570-10-60-10+150) \times 2$ shifts $\times 60$ seconds $) / 8,000$ sets $=288$ seconds per set

This takt time is used to control cycle time. For each station, cycle time must be less than or equal to this takt time to ensure that the desired capacity can be achieved.

\subsection{New model study}

New model part prototypes provided by customer for production design is shown in Fig. 1. It requires spot welding of 192 points and arc welding of 12 seams. The right part is assembled by 24 components with spot welding of 96 points and arc welding of 8 seams. The left part is assembled by 22 components with spot welding 96 points and arc welding of 4 seams.


Figure 1: New model part prototypes.

\subsection{Production process design}

Production process design is based on workload balancing concept. This basic concept is used to arrange work station with the division of equal work load which would make the smooth flow of the entire process. In this case, a new production process is designed to have 3 working stations based on workload balancing concept for all 192 welding points and 12 arc seams. It is described below.

Station 1: Spot welding process operated by 2 robots for 64 welding points. The $1^{\text {st }}$ robot is for 32 welding points of the right part. The $2^{\text {nd }}$ robot is for 32 welding points of the left part.

Station 2: Arc welding process operated by a robot with a rotation jig tooling for 12 arc welding seams. This robot operates 8 arc seams of the right part and 4 arc seams for the left.

Station 3: Spot welding process operated by 4 robots for 128 welding points. Two robots are for 64 welding points of the right part. The other two are for 64 welding points for the left part. The simulations of 3D CAD parts and process designs are shown in Figs. 2 and 3, respectively. Fig. 4 presents 3D CAD of final assembly parts.

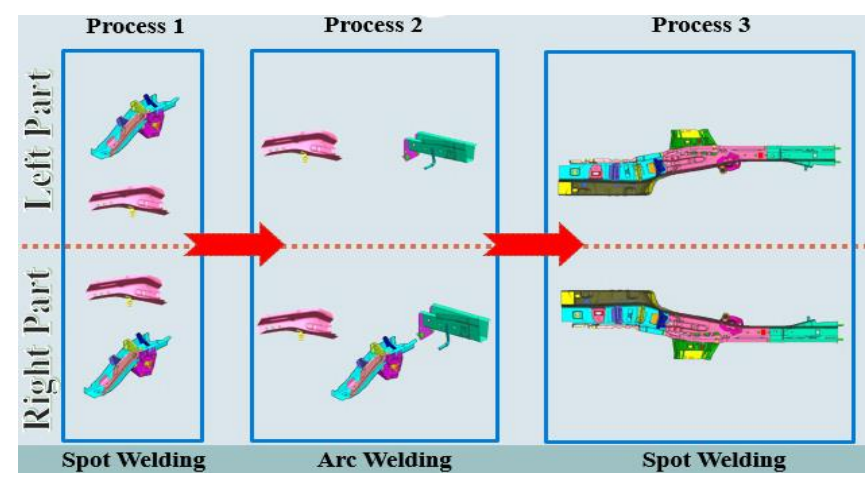

Figure 2: Simulation of 3D CAD parts design. 


\subsection{Manufacturing equipment design}

The equipment supported in the production process is designed in 3D CAD by NX software. Robotics 3D CAD tooling (Torch and Spot Gun) obtains real CAD data from tooling company.

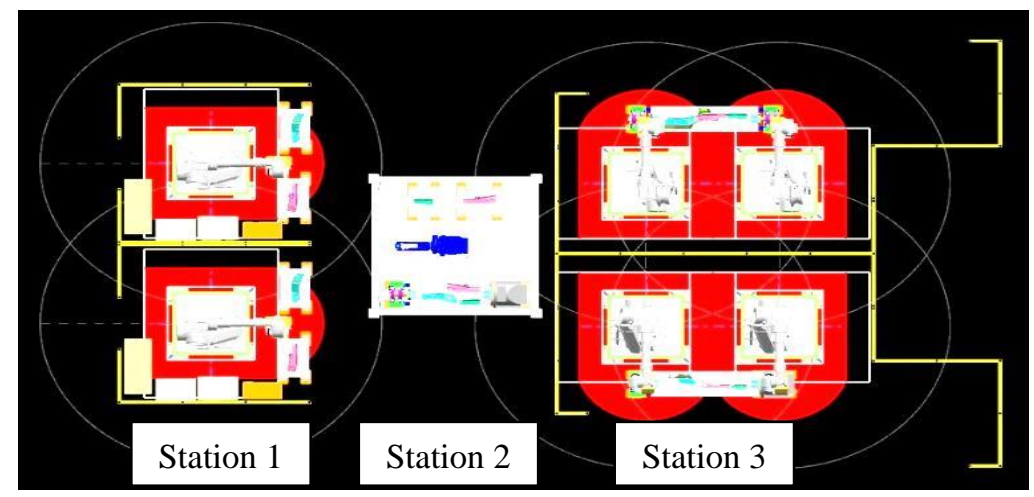

Figure 3: Simulation of production process design.
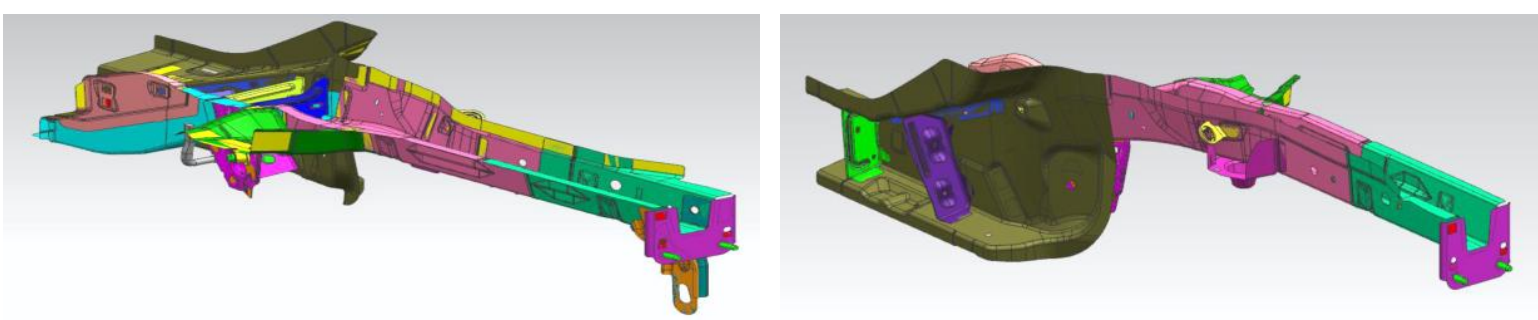

Figure 4: 3D CAD of final assembly parts: right and left.

By using real data of robot's tooling, possible errors in robot simulation is minimized. Thus, the real implementation will provide good results. The design of a new operation of equipment using simulation enable user to manually create a device operation which move from one pose to another. In order to create a device operation, user worked with a device which has at least two defined poses. These operations of device have been brought into process simulation. Then the cycle time of each working station will be generated by robot simulation program.
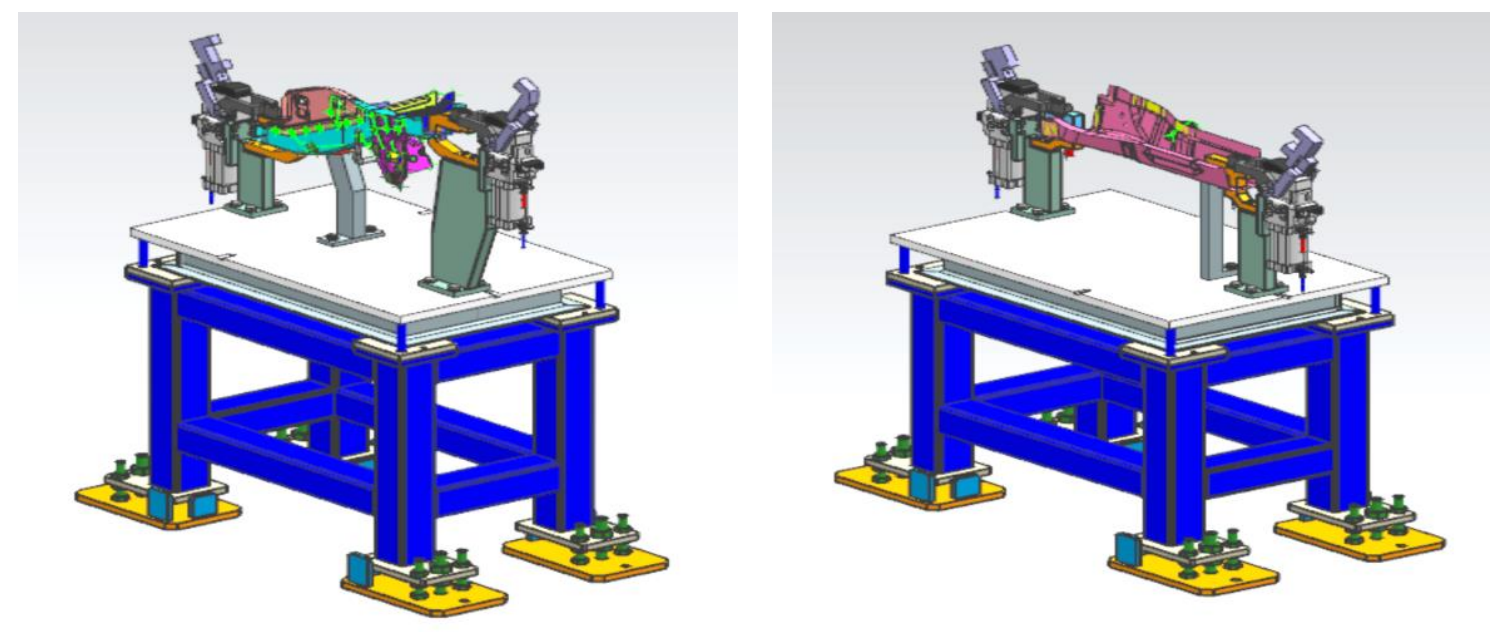

Figure 5: The tooling support for the right part in production process. 



Figure 6: The tooling support for the left part in production process.

\subsection{Production planning}

Given time resource shown in Table I and the design of working station in section 2.2 and 2.3, production planning has been designed and optimized. To compare different proposed alternatives base on labour and machine (robot) resources, three scenarios of production plans are brought into consideration.

Scenario 1: Set up of regular 19 working hours of 2 shifts.

Scenario 2: Set up of regular 19 working hours of 2 shifts with additional 2 hours overtime.

Scenario 3: Set up of regular 19 working hours of 2 shifts with additional 4 hours overtime.

Normally, working period for a worker is 9 hours and 30 minutes with 1 hour and 20 minutes break. Therefore, the actual working hours of a worker is 490 minutes ( 8 hours and 10 minutes). In addition, each shift has 2 hours and 30 minutes (150 minutes) of overtime available. Therefore, total available time of each shift is 640 minutes. By this design, each station requires only one worker to load and unload parts onto jigs which is the minimum number of worker.

\section{RESULTS AND DISCUSSION}

This section illustrates the results of process design. Section 3.1 explains the results of robot simulation for each station and section 3.2 illustrates the results of plant simulation for process planning of all three stations, respectively.

\subsection{Results of process design of robot simulation}

1) Results of station 1

The first main process is spot welding process. There are 32 welding points for the right part and 32 welding points for the left part. There are 2 jigs for the right part and 2 jigs for the left part. The tack time of 288 seconds per set for the demand of 8,000 set per month. Therefore, to achieve the goal, each cycle time for all process should be less than takt time. To complete all welding points there should be 1 robot for the right part and 1 robot for the left part as shown in the below Fig. 7. Table II presents the resources of this station and Fig. 8 illustrates the sequence of operations which yields cycle time of 160 seconds. 


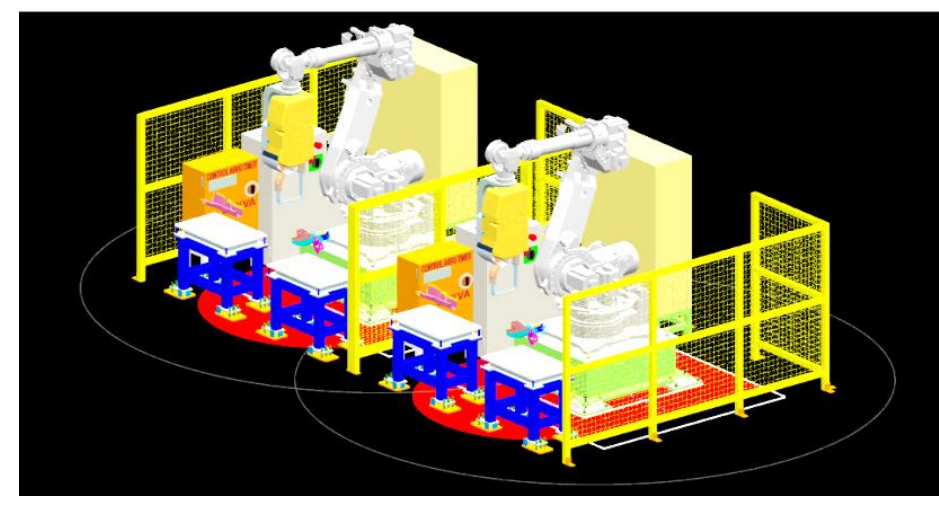

Figure 7: Layout and manufacturing process of station 1.

Table II: Resources of station 1.

\begin{tabular}{|l|l|l|}
\hline Station 1 & Left Part & Right Part \\
\hline Robot & Yaskawa: ES165N & Yaskawa: ES165N \\
\hline Tools & X-Gun & X-Gun \\
\hline Welding Points & 32 welding points & 32 welding points \\
\hline Cycle Time & \multicolumn{2}{|c|}{160 seconds } \\
\hline
\end{tabular}

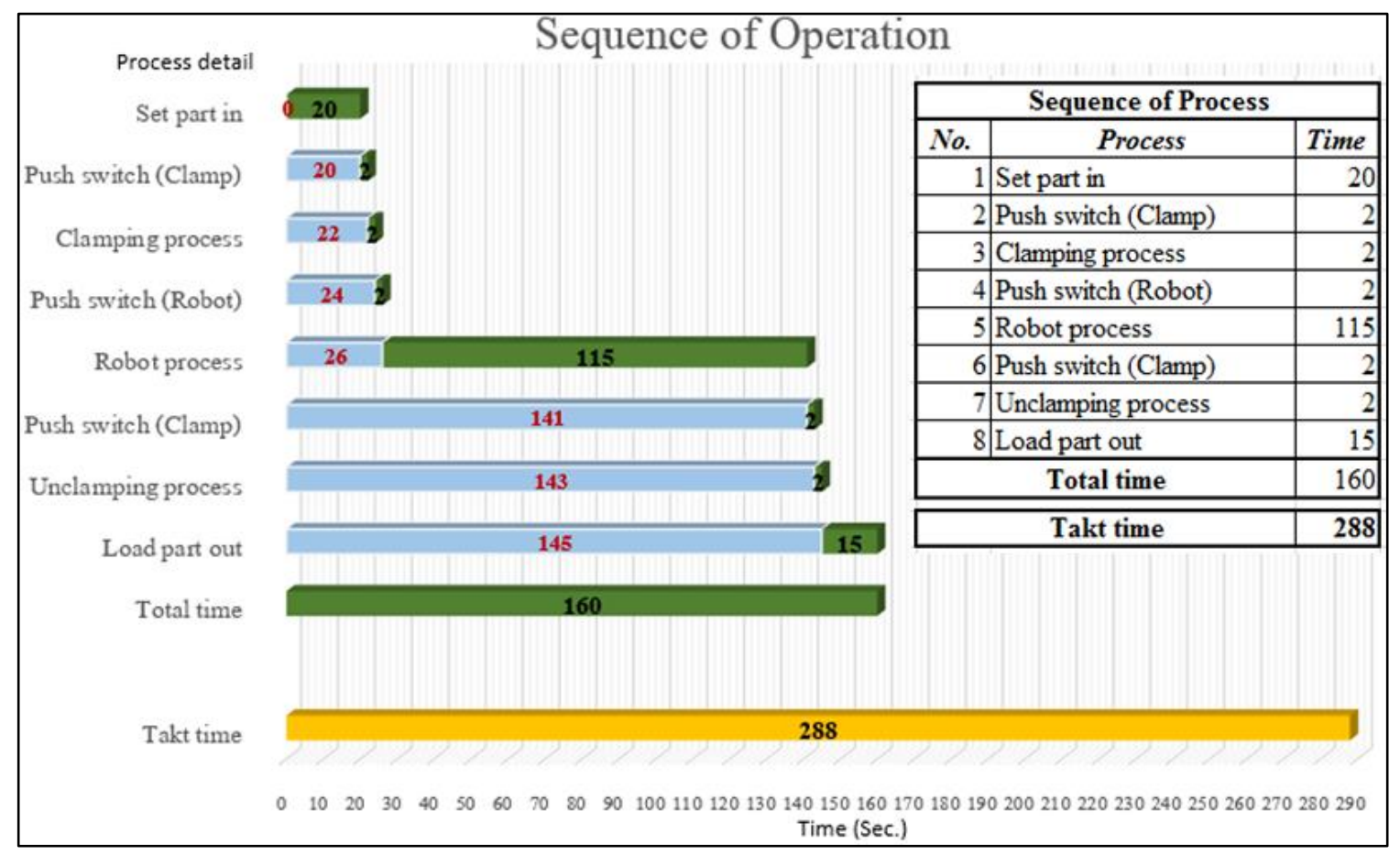

Figure 8: Sequence of operation of station 1.

2) Results of station 2

The second main process is arc welding process. There are 8 arc welding seam for the right part and 4 arc welding seam for the left part. There are 1 rotation jig for the right part and 1 jig for the left part. The tack time is 288 seconds per set for the demand of 8,000 set per month. Therefore, to achieve the goal, each cycle time for all process should be less than takt time. Simulation shows the cycle time of 102 seconds for this station. To complete all arc welding seam with minimum resource, 1 robot is assigned for this station. Fig. 9 presents the layout and process of station 2. Table III shows the required resources. Fig. 10 illustrates the sequence of operation, respectively. 




Figure 9: Layout and manufacturing process of station 2.

Table III: Resources of station 2.

\begin{tabular}{|l|l|l|}
\hline Station 1 & Left Part & Right Part \\
\hline Robot & \multicolumn{2}{|c|}{ Yaskawa: MA1400 } \\
\hline Tools & \multicolumn{2}{|c|}{ Torch } \\
\hline Welding Points & 4 arc welding seams & 8 arc welding seams \\
\hline Cycle Time & \multicolumn{2}{|c|}{102 seconds } \\
\hline
\end{tabular}

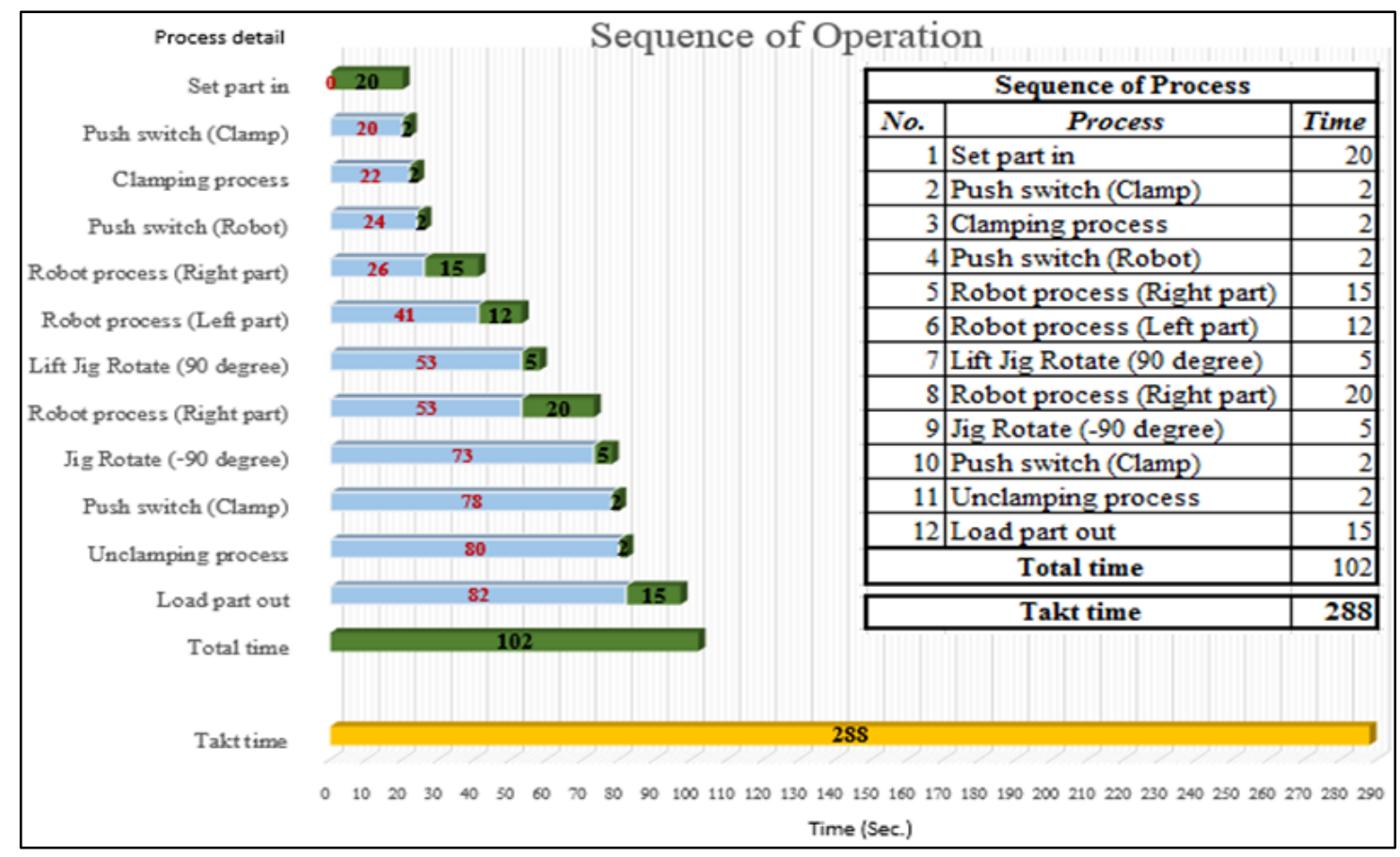

Figure 10: Sequence of operation of station 2.

3) Results of station 3

The third main process is spot welding process. There are 32 welding points for the right part and 32 welding points for the left part. It requires 2 jigs for the right part and 2 jigs for the left part. To complete all welding points there should be 1 robot for the right part and 1 robot for the left part. To achieve the goal of throughput of 8,000 sets per month, each cycle time for all process should be less than takt time. The results of simulation shows that cycle time of this station is 250 seconds which still less than takt time. Fig. 10 shows the layout and the manufacturing process of station 3. Table IV presents the resources and Fig. 12 illustrates the operations. 


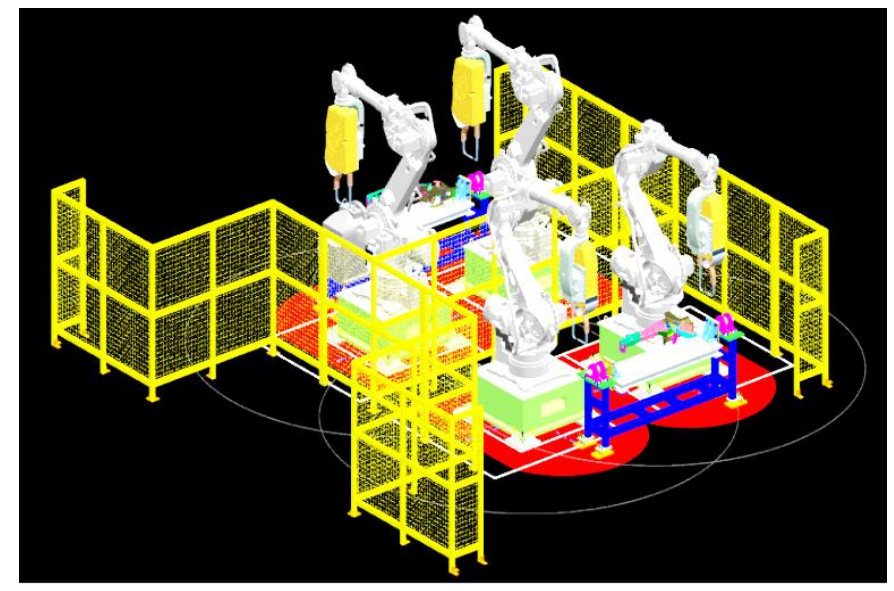

Figure 11: Layout and manufacturing process of station 3.

Table IV: Resources of station 3.

\begin{tabular}{|l|l|l|}
\hline Station 1 & Left Part & Right Part \\
\hline Robot & Yaskawa: ES165N x 2 & Yaskawa: ES165N x 2 \\
\hline Tools & X-Gun x 2 & X-Gun x 2 \\
\hline Welding Points & 64 welding points & 64 welding points \\
\hline Cycle Time & \multicolumn{2}{|c|}{ 250 seconds } \\
\hline
\end{tabular}

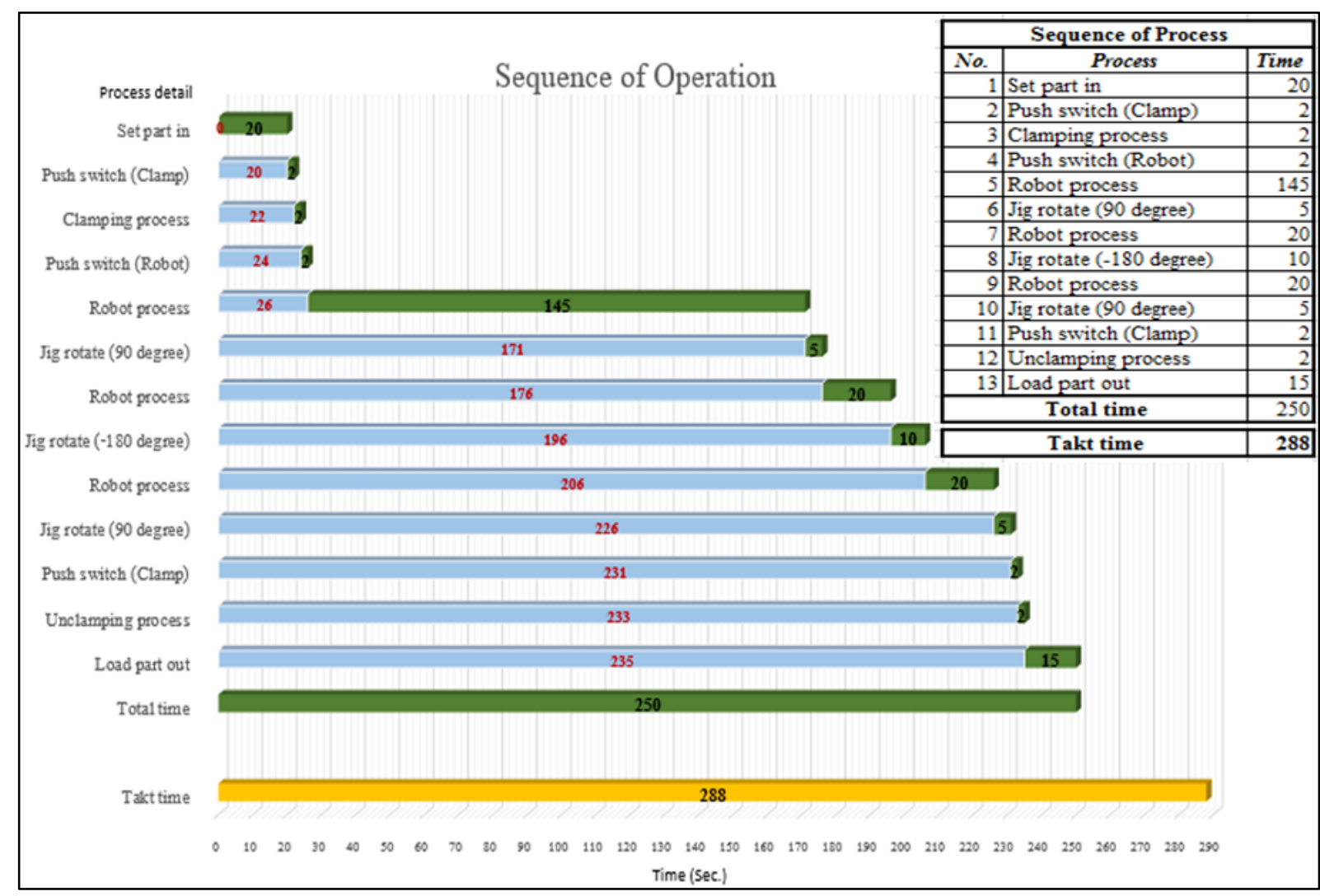

Figure 12: Sequence of operation of station 3.

The simulation of each process provides the designs of operation sequences which yield the desirable cycle time that less than takt time. Once cycle time of each station is ensured to be lower than takt time, the production process can achieve demand level. 


\subsection{Results of production plan of plant simulation}

The previous part explains the process design of robot operation design for each station to control cycle time of each station to be less than takt time. This section discusses about simulation of the entire production process with the given resource of equipment and available time for each station. The goal is to design production process to produce product up to 8,000 sets per month. Three scenarios are conducted to design the production process with the same set of robots but different level of availability of working hours to ensure the throughput rate. Followed the same assumptions in section 3.2, each station has only one worker. Three scenarios are described below.

Scenario 1: Set up of regular 19 working hours of 2 shifts.

The result of this scenario gives throughput of 7,054 sets per month which cannot meet customer demand of 8,000 sets per month. Utilization chart shows station 3 causes the bottleneck and station 2 has the most blocking.

Scenario 2: Set up of regular 19 working hours of 2 shifts with additional 2 hours overtime.

The result of this scenario gives throughput of 8,134 sets per month which can meet customer demand. Utilization chart shows that station 3 causes the bottleneck in the system and station 2 has the most blocking.

Scenario 3: Set up of regular 19 working hours of 2 shifts with additional 4 hours overtime.

The result of this scenario gives throughput of 9,214 sets per month which also can meet customer demand. Utilization chart shows that station 3 causes the bottleneck and station 2 has the most blocking.


Figure 13: Simulation results of scenario 1.
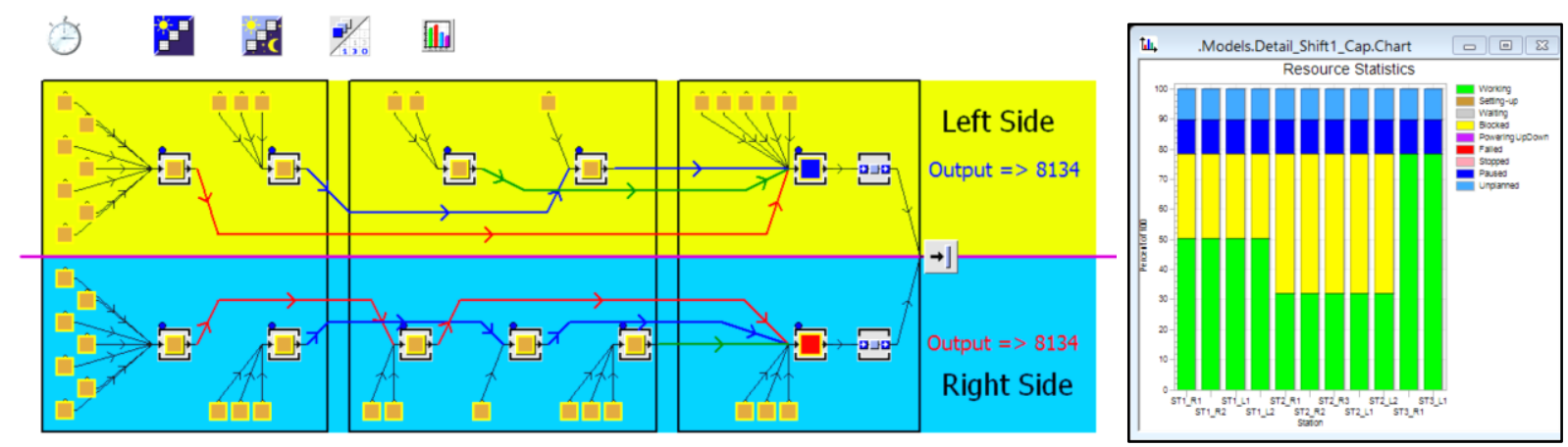

Figure 14: Simulation results of scenario 2. 

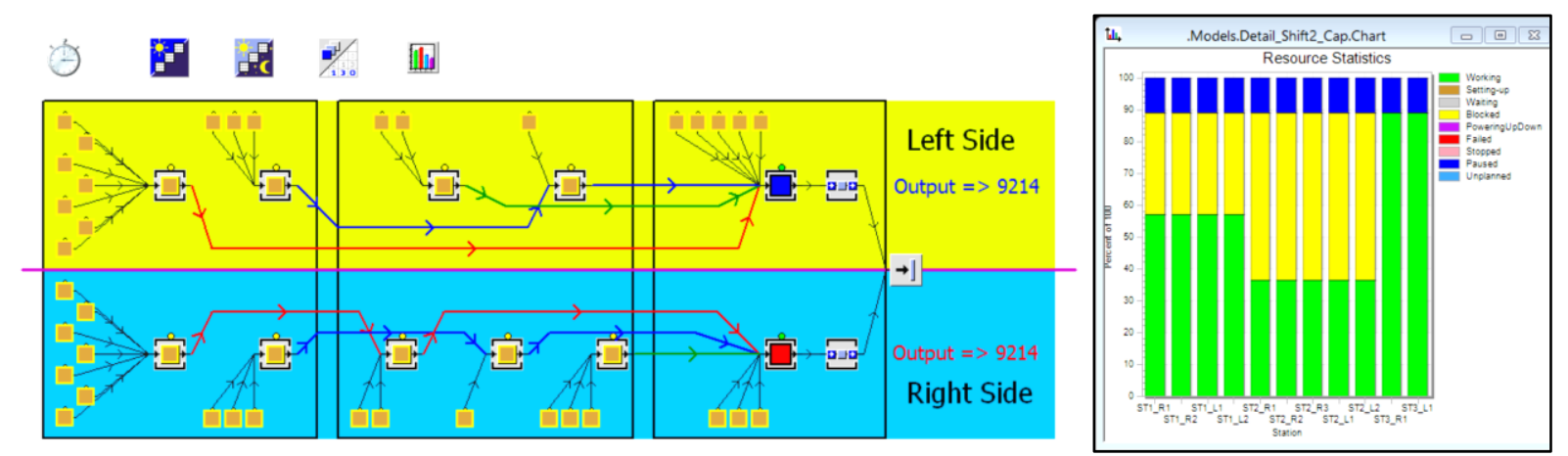

Figure 15: Simulation results of scenario 3.

Without overtime, production process cannot meet customer demand of 8,000 sets per month. Therefore, overtime is needed. Scenarios 2 and 3 show different level of overtime which can provide sufficient throughput to meet customer demand. Cost-Benefit analysis should be brought into account to measure and compare the benefit of the increase of capacity versus the cost of overtime wages between scenario 2 and 3. However, both scenarios 2 and 3 have enough capacity to ensure that production can produce enough throughput to meet customer demand.

\section{CONCLUSION}

A new production process has been designed to meet capacity up to 8,000 sets per month to meet customer demand. That means the cycle time of each work station must less than the takt time. The results show that process design consists of three main stations. Station 1 is spot welding process which is operated by 2 robots and has a cycle time of 160 seconds to finish 64 welding points ( 32 welding points for the right and 32 welding points for the left parts). Station 2 is arc welding process which is operated by 1 robot with a cycle time of 102 seconds to finish 12 arc welding seams ( 8 arc seams for the right and 4 arc seams for the left parts). Station 3 is spot welding process which is operated by 4 robots with a cycle time of 250 seconds to finish 128 welding points (64 welding points or the right and 64 welding points for the left parts). Each of work station has cycle time less than tack time of 288 seconds.

The production planning is made to design how to run the production process with the available time. Three scenarios are set up to design working hours input to evaluate process whether it could reach customer monthly demand of 8,000 sets. Three scenarios are proposed.

Scenario 1 is the setup of regular 19 working hours of two shifts with no overtime. The results show capacity of production line of 7,054 sets per month. The exact target of 8,000 sets of throughput could be reached by 35 working days (more than 1 month) which could not meet customer demand. Utilization chart shows that station 3 is the bottleneck and station 2 has the most blocking.

Scenario 2 is the setup of regular 19 working hours of two shifts with additional two hours overtime. Overtime can be assigned in any shift because it is not beyond the limitation of 150 minutes ( 2.5 hours) per shift. The capacity of the production line is 8,134 set per month. The exact target of 8,000 sets of throughput could be reached by 30 working days ( 1 month) which could meet customer demand. Utilization chart shows that station 3 is the bottleneck and station 2 has the most blocking.

Scenario 3 is the setup of regular 19 working hours of two shifts with extra four hours overtime. Overtime needs to be assigned for 2 hours at shift 1 and another 2 hours at shift 2, because overtime is available only 150 minutes for each shift as presented in Table I. The capacity of the production line is 9,214 set per month. The exact target of 8,000 sets of 
throughput could be reached by 27 working days (less than 1 month) which could meet customer demand. Utilization chart shows that station 3 is the bottleneck and station 2 has the most blocking.

For further study, in case that the demand of customer continue to be increased, station 3 should be firstly taken in to account as it is now the system bottleneck. Since time slot of total 5 hours of overtime of both shifts is almost filled, the possible way of capacity enhancement is to reduce bottleneck on station 3 by reconsider line balancing. This station can be spitted to two stations to reduce cycle time. However, more workers will be required to operate the new station. In such case, Cost-Benefit analysis could be used to evaluate alternatives to decide the best solutions.

As a conclusion, this study presents computer simulations to design automotive part production process. Robot simulation provides three dimension robot (3D CAD) simulation for robotic work stations designed to meet the desired cycle time with minimum chance of robot collision and minimum number of required robots in the system. Plant simulation provides production planning design in order to produce product which could meet the desired capacity and customer needs with minimum resource of labour. The simulation results provide very supportive alternative solutions for decision making for the case study company.

\section{ACKNOWLEGEMENT}

This research was funded by King Mongkut's University of Technology North Bangkok (KMUTNB). Contract number KMUTNB-GOV-59-48.

\section{REFERENCES}

[1] Andradottir, S.; Healy, K. J.; Withers, D. H.; Nelson, B. L. (Eds.). (1997). Proceedings of the 1997 Winter Simulation Conference, Association for Computing Machinery, New York

[2] Supsomboon, S.; Vajasuvimon, A. (2016). Simulation model for job shop production process improvement in machine parts manufacturing, International Journal of Simulation Modelling, Vol. 15, No. 4, 611-622, doi:10.2507/IJSIMM15(4)3.352

[3] Heinicke, M. U., Hickman, A. (2010). Eliminate bottlenecks with integrated analysis tools in eMPlant, Proceeding of the 2000 Winter Simulation Conference, 229-231

[4] Muhammad, N.; Feng, C. J. (2014). A methodology to optimize value in discrete event simulation for production planning and control studies, Proceedings of the International Conference on Industrial Engineering and Operations Management, 676-684

[5] Ülgen, O. M.; Upendram, S. S. (1997). Productivity simulation in the automotive industry, Proceedings of the SCS 1997 Simulation Multiconference, 199-204

[6] Trakultongchai, A.; Supsomboon, S.; Limtanyakul, K. (2013). Process simulation and improvement of automotive paint shop, International Journal of Mining, Metallurgy \& Mechanical Engineering (IJMMME), Vol. 1, No. 1, 1-4

[7] Thürer, M.; Stevenson, M.; Silva, C.; Qu, T (2017). Drum-buffer-rope and workload control in high-variety flow and job shops with bottlenecks: An assessment by simulation, International Journal of Production Economics, Vol. 188, 116-127, doi:10.1016/j.ijpe.2017.03.025

[8] Neto, P.; Norberto Pires, J.; Paulo Moreira, A. (2010). Robot path simulation: a low cost solution based on CAD, 2010 IEEE Conference on Robotics Automation and Mechatronics, 333-338, doi:10.1109/RAMECH.2010.5513169

[9] Curcio, D.; Longo, F.; Mirabelli, G. (2007). Manufacturing process management using a flexible modeling and simulation approach, Proceedings of the Winter Simulation Conference, WSC 2007, 1594-1600, doi:10.1109/WSC.2007.4419778

[10] Urrea, C.; Kern, J. (2016). Design, simulation and comparison of controllers for a redundant robot, Case Studies in Mechanical Systems and Signal Processing, Vol. 3, 9-21, doi: $10.1016 / \mathrm{j} . \mathrm{csmssp} .2015 .12 .001$ 
[11] Yang, Y.; Song, Y.; Pan, H.; Cheng, Y.; Feng, H.; Wu, H.; (2016). Visual servo simulation of EAST articulated maintenance arm robot, Fusion Engineering and Design, Vol. 104, 28-33, doi:10.1016/j.fusengdes.2016.01.024

[12] Deros, B. M.; Mohamad, D.; Idris, M. H. M.; Rahman, M. N. A.; Ghani, J. A.; Ismail, A. R. (2011). Setup time reduction in an automotive battery assembly line, International Journal of Systems Applications, Engineering \& Development, Vol. 5, No. 5, 618-625

[13] Stankovic, I., Car, Z., Barisic, B. (2011). Comparative simulations of the heavy machining production system, Engineering Review, Vol. 31, No. 1, 1-11

[14] Kadar, B.; Pfeiffer, A.; Monostori, L. (2004). Discrete event simulation for supporting production planning and scheduling decisions in digital factories, Proceedings of the $37^{\text {th }}$ CIRP International Seminar on Manufacturing Systems, 444-448

[15] Haider, A.; Mirza, J.; Ahmad, W. (2015). Lean capacity planning for tool room: An iterative system improvement approach, Advances in Production Engineering \& Management, Vol. 10, No. 4, 169-184, doi:10.14743/apem2015.4.200

[16] Maria, A. (1997). Introduction to modeling and simulation, Proceedings of the 1997 Winter Simulation Conference (WSC '97), 7-13, doi:10.1109/WSC.1997.640371

[17] Sargent, R. G. (2011). Verification and validation of simulation models, Proceedings of the 2011 Winter Simulation Conference (WSC 2011), 183-198, doi:10.1109/WSC.2011.6147750

[18] Güçdemir, H.; Selim, H. (2017). Customer centric production planning and control in job shops: A simulation optimization approach, Journal of Manufacturing Systems, Vol. 43, Part 1, 100-116, doi:10.1016/j.jmsy.2017.02.004

[19] Lang, S.; Reggelin, T.; Wunder, T. (2017). Mesoscopic simulation models for logistics planning tasks in the automotive industry, Procedia Engineering, Vol. 178, 298-307, doi:10.1016/ j.proeng.2017.01.118

[20] Ho, Y.-L. (2015). Staged improvement of delivery-oriented production, International Journal of Simulation Modelling, Vol. 14, No. 1, 17-27, doi:10.2507/IJSIMM14(1)2.272

[21] Sasiadek, M. (2015). Planning and analysis of mechanical assembly sequences in design engineering - Part I: The method, Technical Gazette, Vol. 22, No. 2, 337-342, doi:10.17559/TV20130428110530

[22] Kostic, Z.; Cvetkovic, D.; Jevremovic, A.; Radakovic, D.; Popovic, R.; Markovic, D. (2013). The development of assembly constraints within a virtual laboratory for collaborative learning in industrial design, Technical Gazette, Vol. 20, No. 5, 747-753

[23] Banduka, N.; Veza, I.; Bilic, B. (2016). An integrated lean approach to Process Failure Mode and Effect Analysis (PFMEA): A case study from automotive industry, Advances in Production Engineering \& Management, Vol. 11, No. 4, 355-365, doi:10.14743/apem2016.4.233 